\title{
Multiletramentos e ensino de língua portuguesa na educação básica: uma proposta didática para o trabalho com (hiper)gêneros multimodais
}

\author{
Multiliteracies and teaching portuguese language in basic education: \\ a didactic proposal for work with multimodal (hyper)genres
}

\section{Fernanda Maria Almeida dos Santos}

Universidade Federal do Recôncavo da Bahia - UFRB - Bahia - Brasil

\begin{abstract}
Resumo: Na contemporaneidade, o desenvolvimento e uso contínuo das Tecnologias Digitais têm modificado muitas atividades da vida humana e desencadeado processos de ensino e aprendizagem cada vez mais interativos, dinâmicos e plurais, exigindo dos cidadãos diferentes habilidades de leitura e de escrita inter-relacionadas à multiplicidade de discursos, textos, sujeitos e culturas. Sob essa ótica, o presente trabalho apresenta uma discussão sobre os multiletramentos, analisando como o trabalho com gêneros/hipergêneros multimodais, por meio da utilização das interfaces digitais, pode colaborar para o desenvolvimento das práticas de letramentos nos anos finais do ensino fundamental. O referencial teórico do trabalho concilia os postulados de Cope e Kalantzis (2009), Kress (2000), Kress e Van Leeuwen (2006 [1996]), NLG (1996) e outros, sobre multiletramentos, multimodalidade e aprendizagem em ambientes virtuais. Argumenta-se, por meio de uma metodologia de investigação explicativa, com método de abordagem qualitativo, que as práticas de multiletramentos intensificam o desenvolvimento das competências linguísticas dos sujeitos, potencializando o aprendizado da leitura e da escrita.
\end{abstract}

Palavras-chave: Tecnologias digitais. Multiletramentos. Gêneros multimodais. Aprendizagem.

\begin{abstract}
In contemporary times, the development and continuous use of Digital Technologies has modified many activities of human life and has triggered increasingly interactive, dynamic and plural teaching and learning processes, requiring different citizens of reading and writing skills related to multiplicity of discourses, texts, subjects and cultures. From this perspective, the present work presents a discussion about multiliteracies, analyzing how work with multimodal genres/hypergenres, through the use of digital interfaces, can contribute to the development of literacy practices in the final years of elementary education. The theoretical framework of the work reconciles the postulates of Cope e Kalantzis (2009), Kress (2000), Kress e Van Leeuwen (2006 [1996]), NLG (1996) and others on multiliteracies, multimodality and learning in virtual environments. It is argued, through an explanatory research methodology, with a method of qualitative approach, that the practices of multiliteracies intensify the development of the linguistic competences of the subjects, enhancing the learning of reading and writing.
\end{abstract}

Keywords: Digital Technologies. Multiliteracies. Multimodal genres. Learning. 


\section{Introdução}

No mundo contemporâneo, a intensificação dos processos de produção e desenvolvimento das Tecnologias Digitais da Informação e Comunicação, bem como a popularização do acesso a essas tecnologias, tem causado alterações na vida e nas (rel)ações humanas e, consequentemente, nos valores e nas atitudes dos sujeitos, ao mesmo tempo em que promovem sua inserção e participação no contexto histórico e sociocultural.

De fato, num cenário em que as tecnologias mais contemporâneas se incorporam de diversas maneiras à vida humana, as relações estabelecidas entre os indivíduos são muito mais globais e interativas, o conhecimento ganha plasticidade e o contato com a escrita torna-se cada vez mais necessário, seja para a constituição (ou transmutação) de gêneros do discurso, seja para o desenvolvimento de novas práticas de uso social da leitura e escrita. Nesse sentido, é fundamental que a instituição escolar pós-moderna, fruto das relações sociais e da construção do conhecimento via cultura escrita, contemple as múltiplas cenas de letramentos sociais - multimodais e multiculturais - por meio da utilização de diferentes interfaces tecnológicas. Novas tecnologias, novos sujeitos e novos modos de aprendizagem demandam, evidentemente, novos saberes docentes e novas propostas educacionais.

Observa-se, contudo, que as instituições de ensino, em sua maioria, não têm acompanhado as mudanças tecnológicas propiciadas pelas agências de desenvolvimento de alta tecnologia e impulsionadas pela participação cada vez mais intensa dos indivíduos. Mesmo com o processo de informatização das escolas nos finais da década de 1990, vinte anos depois pouca coisa mudou. Muitas escolas ainda parecem estar alheias à atual realidade. Uma pesquisa publicada pelo Núcleo de Informação e coordenação do Ponto BR - NIC.br (2016), a partir de um estudo longitudinal realizado em 12 escolas da rede pública localizadas em três diferentes regiões do país (nordeste, sul e sudeste) entre os anos de 2010 e 2013, revela que - embora as instituições disponibilizem vários tipos de recursos tecnológicos (TV, data show, scanner, filmadora, computadores e outros) - 0 uso desses equipamentos ainda é bastante limitado. De maneira geral, os docentes têm mais acesso aos computadores do que os alunos, utilizando-os preponderantemente para pesquisas e preparação de aulas e, em menor escala, nas atividades desenvolvidas com os estudantes.

$\mathrm{Na}$ maior parte dos casos, o uso das TIC em sala de aula se dá, principalmente, por meio da exibição de conteúdos em TV Pen Drive, datashow e notebook off-line, com práticas centradas no professor. [...] Outro elemento revelado pelo estudo é o fato de que a tecnologia era um elemento "muito visível" em sala de aula - ou seja, seu uso não estava incorporado e naturalizado nas atividades do dia a dia. Por isso, em certas situações, a presença do computador ou de outros equipamentos na sala gerava tumulto e até desorganizava as atividades pedagógicas, em vez de contribuir para que elas fossem mais interessantes e produtivas. (NIC.br, 2016, p.74-75)

Mediante um cenário educacional em que o uso das Tecnologias Digitais em sala de aula ainda é considerado um obstáculo - tanto por fatores de ordem infraestrutural, quanto por possíveis lacunas na formação docente -, como promover mudanças? Que estratégias podem ser utilizadas para aliar as interfaces digitais ao processo de ensino e aprendizagem de língua portuguesa na educação básica? Como ampliar as práticas de uso social da leitura e da escrita e desenvolver os multiletramentos na escola?

Visando promover reflexões acerca desses questionamentos e reiterar a necessidade de mudanças no ensino de língua portuguesa na educação básica por meio de propostas didáticas voltadas para o uso das Tecnologias Digitais, este artigo apresenta uma discussão sobre os multiletramentos, analisando como o trabalho com gêneros/hipergêneros multimodais, por meio da utilização das interfaces digitais, pode colaborar para o desenvolvimento das práticas de letramentos nos anos finais do ensino fundamental. Inicialmente, discute-se o conceito de multiletramentos, com base nos estudos desenvolvidos pelo New London Group (NLG), bem como reflete-se sobre as necessidades 
contemporâneas de ensino e aprendizagem, em prol de práticas de escrita que extrapolem o contexto escolar. Além disso, apresentam-se estratégias possíveis para o desenvolvimento de práticas de letramentos multimodais no espaço educacional, a fim de demonstrar como a escola contemporânea pode ampliar as competências de leitura e escrita dos estudantes por meio do uso das Tecnologias Digitais da Informação e Comunicação.

Espera-se, com isso, alcançar o objetivo de fomentar uma discussão teórica no campo dos estudos linguísticos, provendo àqueles que se interessam por fenômenos referentes aos letramentos e aquisição da escrita; e, ao mesmo tempo, contribuir com pesquisadores e professores que atuam na educação básica, por meio de discussões sobre variadas possibilidades de aprendizagem da escrita, especialmente aquelas oportunizadas pelo desenvolvimento das tecnologias informacionais.

\section{A teoria dos multiletramentos: construindo significados, transformando representações...}

Num momento da história da humanidade marcado, principalmente, pelos avanços tecnológicos, bem como pela reconfiguração de práticas e de modalidades midiáticas, pela desterritorialização e virtualização dos saberes e pela conectividade global emergem, evidentemente, novas formas de relação com o conhecimento e novos modos de organização da linguagem. Essa nova lógica informacional demanda também processos educacionais mais dinâmicos e desafiadores. No que concerne ao ensino da leitura e da escrita, de modo mais específico, é crucial que a escola - muito mais do que a aprendizagem de elementos técnicos da língua vise ao desenvolvimento de práticas relacionadas à dinamicidade dos gêneros e tipologias textuais que circulam na sociedade contemporânea, englobando portanto - os multiletramentos.

A noção de multiletramentos está associada, por um lado, à multiplicidade cultural e linguística das sociedades pós-modernas e, por outro, à multiplicidade e integração de variados modos de constituição do significado, por meio da utilização de diferentes semioses (cf. NLG, 1996). É importante enfatizar que, embora seja visto como uma novidade por muitos profissionais da educação no Brasil, o termo multiletramentos (e, obviamente, os estudos que o fundamentam) não é tão recente. O vocábulo é uma tradução do inglês multiliteracies, cunhado em 1994 e publicado pela primeira vez, em 1996, no Manifesto $A$ pedagogy of multiliteracies: designing social futures, de autoria do New London Group (NLG) - equipe formada por estudiosos de áreas de especialização distintas (dentre eles, Courtney Cazden, Bill Cope, Norman Fairclough, Jim Gee, Mary Kalantzis, Gunther Kress, Carmen Luke, Sara Michaels e Martin Nakata), os quais têm promovido uma importante discussão acerca dos estudos de letramento e das novas demandas educacionais face à globalização, à tecnologia e à diversidade sociocultural.

Em suas proposições, os membros do NLG (1996, p.64) se embasam em dois argumentos que se apoiam na "nova" ordem cultural, institucional e global: i) "[...] a crescente multiplicidade e integração de modos de construção de significado, em que o textual está integrado ao visual, ao áudio, ao espacial e ao comportamental, e assim por diante"; ii) a "[...] crescente diversidade local e conexão global. Lidar com diferenças linguísticas e diferenças culturais agora tornou-se central para a pragmática das nossas vidas trabalhadoras, civis e privadas" (tradução nossa). Os autores defendem, desse modo, uma proposta de ensino que contemple e dê visibilidade às dimensões profissionais, pessoais e cívicas dos sujeitos. Para tanto, procuram substituir as concepções estáticas de representação do significado por uma concepção mais dinâmica, embasada no conceito de design. O design é definido pelos estudiosos como um processo de constituição de significados que se dá por meio da inter-relação entre três diferentes etapas: avaliable design, designing e redesigning. Nessa perspectiva, ao ter contato com as diferentes formas de representação material e simbólica disponíveis (avaliable designs) e planejar, construir e desenvolver conteúdos (designing), o 
estudante - criticamente - reorganiza o conhecimento e reconfigura (redesigning) suas identidades, oportunidades e olhares acerca do mundo em que vive.

No entanto, uma reflexão acerca da teoria nos leva a perceber que um conteúdo também pode ser trabalhado de modo tradicional com base nesse modelo. Um professor que ministra aulas de língua portuguesa para uma turma do $6^{0}$ ano do ensino fundamental, por exemplo, pode propor um trabalho com histórias em quadrinhos, solicitando inicialmente - a leitura silenciosa de um texto escrito e ilustrado. Nessa primeira etapa, estará proporcionando aos alunos o contato direto com diferentes formas de representação. Mas, em seguida, o docente pode solicitar apenas que os alunos reescrevam o texto, corrigindo os possíveis "desvios" linguísticos presentes na narrativa. Nesse caso, utilizará o texto para a realização de atividades gramaticais mecânicas, desenvolvendo os conhecimentos de modo acrítico e contribuindo assim - para transformar um material mais reflexivo em um texto de cunho normativo. Desse modo, levanta-se o seguinte questionamento: o que, de fato, diferencia a aquisição do conhecimento na perspectiva da teoria do design, se comparada aos métodos mais tradicionais de ensino?

Conforme o manifesto do NLG, o que distingue a pedagogia dos multiletramentos e as concepções educacionais mais conservadoras é a prática, o como fazer. Por isso, fundamentando-se no conceito de design, o NLG (1996, p. 65) sugere que a pedagogia dos multiletramentos possa ser desenvolvida por meio das seguintes etapas: prática situada ("experimentação" - nessa etapa, os estudantes se baseiam na experiência de fazer significado nos mundos da vida, no domínio público e nos locais de trabalho); instrução explícita ("conceitualização" nessa fase, os alunos desenvolvem uma metalinguagem explícita de Design); enquadramento crítico ("análise" - nessa etapa, os sujeitos interpretam o contexto social e o propósito dos Designs de significado); e prática transformada ("aplicação" - nessa fase, os estudantes, como criadores de significados, se tornam Designers de futuros sociais). Nessa perspectiva, um professor que ministra aulas de língua portuguesa para uma turma do $6^{\circ}$ ano do ensino fundamental, ao propor um trabalho com histórias em quadrinhos, desenvolverá atividades linguísticas não com foco na correção do texto a partir de aspectos normativos, mas com base na reflexão acerca das imagens e do uso da língua (nas modalidades oral e escrita), conforme os diferentes contextos de uso, as particularidades de cada sujeito e os distintos propósitos comunicativos, potencializando a construção de saberes e significados.

Certamente, à medida que o designer constrói significados, eles exercem sua subjetividade no processo de representação. Esses significados são sempre novos e, por isso, se reconstroem, resultando em subjetividade transformada e, desse modo, em aprendizagem (cf. COPE; KALANTZIS, 2009). Notase, portanto, que o "[...] desenvolvimento de uma teoria da aprendizagem em que a transformação ou o redesenho é uma microdinâmica central é um dos principais avanços na teoria dos multiletramentos desde meados da década de 1990" (COPE; KALANTZIS, 2009, p.178, tradução nossa). Nos modelos anteriores de letramento, o redesigning não se torna necessariamente uma prática transformadora.

Na visão de Cope e Kalantzis - integrantes do NLG:

[...] uma pedagogia transformadora é baseada tanto em uma visão realista da sociedade contemporânea (como a escolaridade oferece acesso cultural e material a suas instituições de poder?) como em uma visão emancipatória de possíveis caminhos para melhoria em nosso futuro humano (como podemos fazer o melhor, o mais igual, o menos humanamente e ambientalmente prejudicial mundo?). $\mathrm{Na}$ medida em que estes dois objetivos poderiam às vezes estar em desacordo, uma pedagogia transformadora poderia ser usada para suportar qualquer visão. (2009, p.184, tradução nossa)

Sem dúvida, ao propor processos de aprendizagem dinâmicos, reais e emancipatórios, nos quais "[...] todas as formas de representação, incluindo a língua, devem ser consideradas processos dinâmicos de transformação, em vez de processos de 
reprodução" (COPE; KALANTZIS, 2009, p.175, tradução nossa), a Pedagogia dos Multiletramentos permite percursos alternativos de aprendizagem e de engajamento dos indivíduos. Nesse contexto, a multiculturalidade característica das sociedades globalizadas é cada vez mais reconhecida e valorizada; os sujeitos "transformam-se" de modo individual, conforme suas singularidades e identidades; e o processo de constituição conhecimento é sempre novo.

A abordagem dos multiletramentos sugere, portanto, uma pedagogia voltada para a cidadania, centrada nos aprendentes como agentes em seus próprios processos de conhecimento. Tem como foco uma aprendizagem aberta às diferenças, mudanças e inovações. Contudo, para dar conta da multiplicidade cultural que se inter-relaciona e da pluralidade de textos que circulam nas sociedades contemporâneas, a Pedagogia dos Multiletramentos também considera a associação entre a crescente variedade de formas de textos e as Tecnologias da Informação e Comunicação. Isso inclui

compreensão e domínio de formas de representação utilizadas nos ambientes virtuais de interação, as quais - muitas vezes - englobam diferentes modos de significado.

Sendo assim, outra ideia básica da teoria proposta pelo NLG é a de que os multiletramentos são fortemente influenciados pela crescente complexidade e inter-relação entre seis diferentes modos de constituição dos significados, propiciados pelos avanços das Tecnologias da Informação e Comunicação. Trata-se dos modos linguístico (oral e escrito), visual (imagens, leiaute de página, formato de tela), sonoro (músicas, efeitos sonoros), gestual (linguagem corporal, sensualidade), espacial (espaço ambiental e espaço arquitetônico) e multimodal, sendo que "o design multimodal é de ordem diferente dos cinco outros modos de significado; representa os padrões de interconexão entre os outros modos." (NLG, 1996, p.78, tradução nossa) A Figura 1 evidencia essas informações.

Figura 1: Sistematização dos diferentes modos de representação do significado

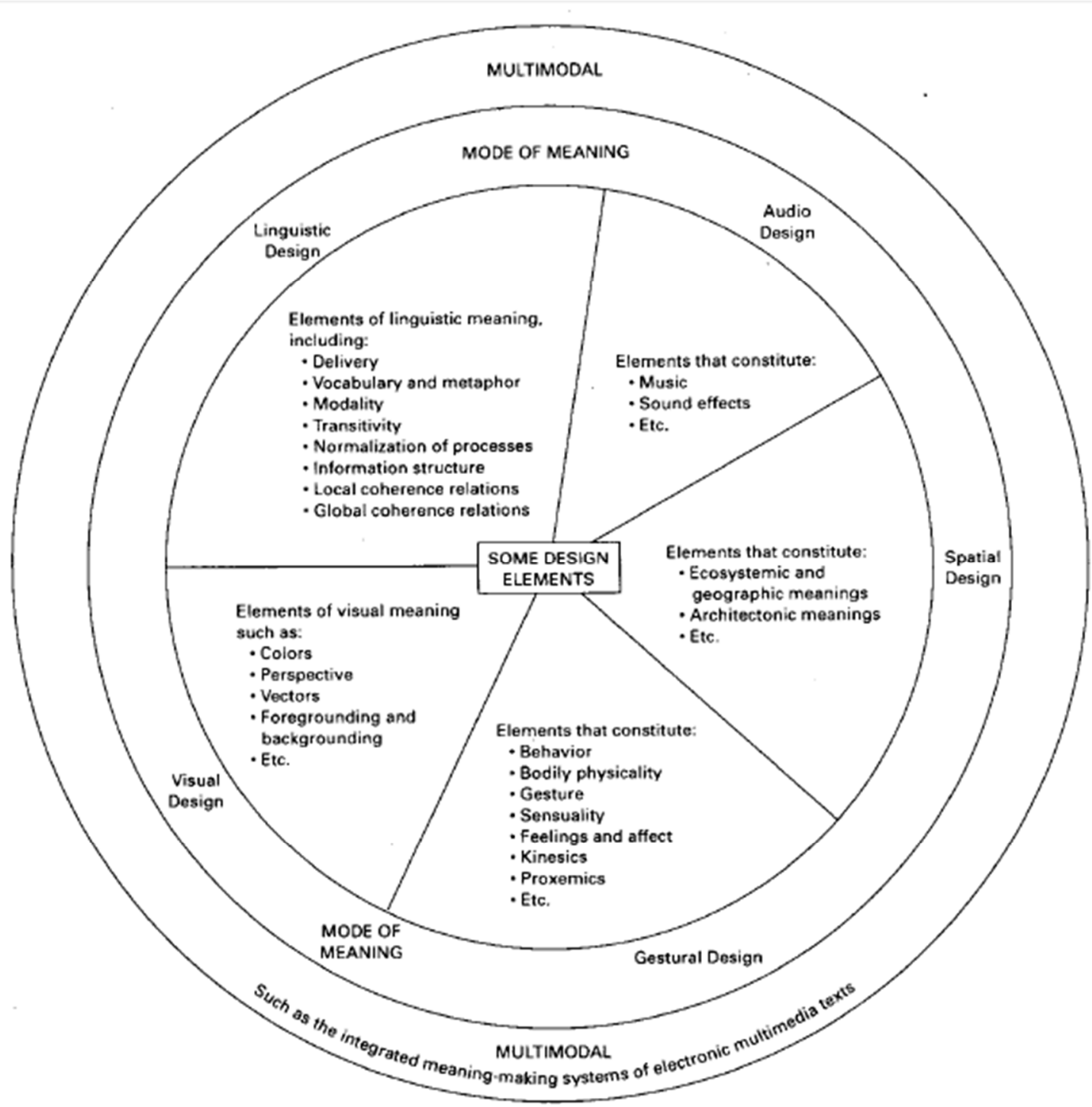

Fonte: NLG, 2016, p.83 
Cope e Kalantzis (2009) acrescentam outras subdivisões à proposta inicial do NLG. Para tanto, consideram os diferentes modos de significado (representacional, social, estrutural, intertextual e ideológico), os cinco órgãos do sentido humano e o aspecto sinestésico da linguagem. Os autores argumentam que os significados podem ser representados por meio da: língua oral, língua escrita, representação visual, representação tátil, representação sonora e representação espacial, as quais se inter-relacionam para a constituição dos textos. De fato, grande parte da nossa experiência de representação dos significados é intrinsecamente multimodal. No entanto, as reflexões em torno da noção de multimodalidade vão além dos aspectos intersemióticos, englobam também fatores intrassemióticos. Nesse caso, há diferentes perspectivas de letramentos a partir do trabalho com textos multimodais. A subseção seguinte trata, de modo mais específico, dessas discussões.

\subsection{Uma breve reflexão acerca da noção de multimodalidade: do intersemiótico ao intrasemiótico}

Embora a ideia de multimodalidade
pressuponha novos modos de construção do
significado embasados na nova lógica informacional propiciada pelo contínuo desenvolvimento das Tecnologias Digitais da Informação e Comunicação, os textos e representações multimodais estão presentes na vida e nas relações humanas desde épocas bem anteriores à denominada Era da Informação. O próprio sistema de escrita alfabética é multimodal em seu modo de constituição.

Conforme Kress (2000) e Cope e Kalantzis (2009), todos os textos são multimodais, inclusive os escritos e orais. "A língua escrita está intimamente ligada ao visual em seu uso de espaçamento, leiaute e tipografia. A língua falada está intimamente associada ao modo áudio no uso de entonação, inflexão, afinação, tempo e pausa." (COPE; KALANTZIS, 2009, p.179, tradução nossa). De fato, na produção oral estão presentes, além dos elementos linguísticos, o ritmo, a sonoridade, a entonação. Já na escrita, o tamanho, a fonte e as cores das letras, bem como a seleção do suporte e do tipo de papel contribuem para a construção dos significados. Na verdade, a escrita é também visual; assim como a produção oral é sempre uma representação sonora. E, embora uma forma de representação sempre tenha maior proeminência que outra(s), os diferentes modos de representação se inter-relacionam. E mais: o significado expresso em um modo não pode ser direta e completamente manifestado por outro modo.

Como as estruturas linguísticas, as estruturas visuais apontam para interpretações particulares das formas de experiência de interação social. Até certo ponto, estas também podem ser expressas linguisticamente. Os significados pertencem à cultura, em vez de pertencerem a modos semióticos específicos. (KRESS e VAN LEEUWEN, 2006 [1996], p.2, tradução nossa)

Refletindo acerca desses aspectos, Kress e Van Leeuwen (2006), ao proporem uma Gramática do Design Visual, apresentam um panorama da semiótica, fundamentando-se em um conjunto de hipóteses:

(a) as sociedades humanas usam uma variedade de modos de representação; (b) cada modo tem, inerentemente, diferentes potenciais de representação, diferentes potenciais para a criação de significado; (c) cada modo possui avaliação social específica em contextos sociais específicos; (d) potenciais diferentes para construir significado podem implicar diferentes potencialidades para a formação de subjetividades; (e) os indivíduos usam uma variedade de modos representacionais e, portanto, possuem uma variedade de meios de construir significado, cada um afetando a formação de sua subjetividade; (f) os diferentes modos de representação não são mantidos discretamente, separadamente, como domínios autônomos fortemente limitados no cérebro, ou como recursos comunicacionais autônomos na cultura, nem são distribuídos discretamente, seja em representação ou em comunicação; (g) os aspectos afetivos do início e as práticas humanas não são distintos de outras atividades cognitivas e, portanto, nunca se separam nem se ausentam do comportamento representacional e comunicativo; (h) cada modo de representação tem um histórico em constante evolução, no qual seu alcance semântico pode se contrair ou expandir ou se mover para diferentes áreas de uso social como resultado dos usos em que é colocado. 
(KRESS; VAN LEEUWEN, 2006 [1996], p.41, tradução nossa, grifo nosso).

Uma das hipóteses elencadas pelos autores reitera a ideia de que os diferentes modos de representação não são mantidos separadamente, nem expressos como recursos comunicacionais autônomos. Nesse sentido, cabe uma reflexão acerca do assunto: todo texto escrito é multimodal? E a oralidade, é sempre multimodal?

Certamente, a resposta a esses questionamentos revela a própria complexidade relativa ao uso da linguagem nas sociedades contemporâneas. No Brasil, vários estudos tratam da multimodalidade na perspectiva da integração entre diferentes sistemas de signos. $O$ nosso posicionamento é que um gênero de texto pode ser multimodal por integrar representações visuais, sonoras, espaciais, gestuais e linguísticas (a exemplo dos vídeos) ou por representar, por meio de uma mesma semiose, diferentes modos de significação (a exemplo dos poemas concretos, que mesclam na escrita diferentes formatos, cores e tamanhos de letras). Mas acreditamos também que um gênero de texto escrito, como a redação, pode ser monomodal, quando - além de não integrar outras semioses mantém uma homogeneidade de fontes, cores e formato de letras. Do mesmo modo, um texto oral, que não revela diferentes ritmos, pausas e entonações é também um texto monomodal.

Assim, se por um lado alguns textos apresentam uma monomodalidade ou multimodalidade dentro do mesmo sistema de signos; por outro lado, observa-se que, em determinados textos, diferentes sistemas semióticos se mesclam. Aliás, na contemporaneidade, as Tecnologias da Informação e Comunicação propiciaram a mescla de cinco diferentes semioses num mesmo gênero ou hipergênero textual, o que não era possível em outros momentos históricos. Por isso, defende-se - neste trabalho - a existência de dois diferentes tipos de multimodalidade. O primeiro tipo corresponde aos diferentes modos de representação do significado num mesmo sistema de signos: multimodalidade intrassemiótica. Já o segundo tipo diz respeito aos diferentes modos de representação do significado num mesmo sistema de signos por meio de distintos sistemas de signos: multimodalidade intersemiótica. Um gênero de texto pode apresentar apenas um desses tipos de multimodalidade ou ambos os tipos. Pode também ser monomodal ao invés de multimodal.

Os aspectos monomodais têm sido historicamente privilegiados nas práticas de letramento escolar.

No exterior da escola, no entanto, as imagens desempenham um papel cada vez maior e não apenas em textos para crianças. Seja na mídia impressa ou eletrônica, seja em jornais, revistas, CD-ROM ou sítios, seja como materiais de relações públicas, propagandas ou como materiais informativos de todos os tipos, a maioria dos textos agora envolve uma interação complexa de texto escrito, imagens e outros elementos gráficos ou sonoros, concebidos como entidades coerentes (muitas vezes no primeiro nível visual e não verbal) por meio do leiaute. Mas a habilidade de produzir textos multimodais deste tipo, por mais importante que seja seu papel na sociedade contemporânea, não é ensinada nas escolas. (KRESS; VAN LEEUWEN, 2006 [1996], p.16-17, tradução nossa)

Portanto, cabe à escola pós-moderna promover a atuação dos educandos em práticas reais de uso social da leitura e da escrita por meio do trabalho com textos multimodais intersemióticos e intrassemióticos, valorizando as distintas formas de representação e os diferentes potenciais para a criação de significado. Por isso, é preciso que os docentes estejam atentos aos diferentes modos de uso da linguagem e percebam a língua e os outros modos de constituição do sentido como elementos dinâmicos, os quais são constantemente reconstruídos pelos sujeitos à medida que esses se empenham para alcançar os mais variados propósitos culturais.

\section{0 trabalho com textos multimodais nas aulas de língua portuguesa: uma proposta didática}

Nesta seção do trabalho, será apresentada uma proposta didática fundamentada na Pedagogia dos Multiletramentos (cf. NLG, 1996; KRESS; VAN LEEUWEN, 2006 [1996]; COPE; KALANTZIS, 2009). 
Trata-se, de modo mais específico, de uma proposta de trabalho com textos multimodais intersemióticos e intrassemióticos, que pode desenvolvida nas aulas de língua portuguesa nos anos finais do ensino fundamental por meio da Comunicação Mediada por Computador. Tal escolha ocorreu tanto por conta do processo de informatização do ensino nas escolas da rede pública no Brasil, quanto por acreditarmos que o computador pode se constituir em um elemento estruturante do processo de aprendizagem, desde que seja, é claro, adequadamente utilizado.

Sem dúvida, a utilização do computador conectado à internet vem possibilitando novas formas coletivas/interativas de se ensinar e aprender, articuladas ao contexto em que os indivíduos estão inseridos, contribuindo para a construção do saber, seja por favorecer o uso de variados percursos e linguagens pelos sujeitos, seja por propiciar a constituição de redes colaborativas de comunicação. Desse modo, o computador não é mais o instrumento que ensina o aprendiz, mas um elemento estruturante dos saberes e das experiências dos indivíduos (cf. ALVES, 1998).

Nessa perspectiva, a aplicabilidade das tecnologias digitais no campo educacional tem sido vista por muitos educadores e instituições escolares como uma possibilidade para a modernização do ensino. Entretanto, é preciso considerar que, embora a informática ofereça tecnologias e inovações que podem ser aproveitadas no campo educativo para acessar e aperfeiçoar os mais diversos tipos de conhecimentos, não altera a concepção de ensinoaprendizagem do professor (o computador pode ser utilizado simplesmente como uma ferramenta para edição de textos tradicionais), nem oferece, por si só, subsídios conceituais para a análise e a elaboração de novas ideias. Sendo assim, "não devemos nos equipar com micros por modernismo, sem antes saber se ele pode modernizar o ensino. Não devemos recusá-lo com base em alguma antipatia nostálgica. Finalmente, não devemos adotá-lo pensando que sairemos ilesos da aventura [...]" (MARQUES et. al., 1986, p.20).
Contudo, se utilizado em sala de aula como uma interface simbólica mediadora do conhecimento, aliando-se, portanto, a concepções e práticas pedagógicas interacionais (que enfatizem a exploração de novos tipos de raciocínio, propiciem variadas possibilidades de participação dos sujeitos e estimulem a comunicação com base nos princípios da interatividade), o computador poderá ter caráter diferenciador, sobretudo, no processo de aprendizagem da leitura e da escrita, ao envolver os sujeitos em diferentes práticas de multiletramentos.

É justamente com o objetivo de evidenciar como as interfaces digitais contribuem para as práticas de multiletramentos que serão expostas a seguir algumas sequências didáticas para o trabalho com textos multimodais nas aulas de Língua Portuguesa nos anos finais do ensino fundamental. Embasando-se nas discussões apresentadas na seção 2 deste trabalho, a elaboração das sequências considerou tanto as etapas sugeridas pela Pedagogia dos Multiletramentos, quanto a multimodalidade inter e intrassemiótica dos textos selecionados, conforme expõe o Quadro 1.

Quadro 1 - Proposta didática elaborada para 0 trabalho com textos multimodais nos anos finais do ensino fundamental 


\begin{tabular}{|c|c|c|c|}
\hline $\begin{array}{l}\text { HIPERGÊNER } \\
\text { O TEXTUAL }\end{array}$ & ETAPA & $\begin{array}{c}\text { SEQUÊNCIA } \\
\text { METODOLÓGICA }\end{array}$ & ATIVIDADES \\
\hline \multirow[t]{3}{*}{ HIPERVÍDEO } & $\begin{array}{c}\text { Módulo 1: } \\
\text { EXPERIMENTAÇÃO }\end{array}$ & $\begin{array}{l}\text { Apresentando o } \\
\text { hipergênero }\end{array}$ & $\begin{array}{l}\text { - Observação de hipervídeo sobre o } \\
\text { cyberbullying; } \\
\text { - Prática do jogo Quiz em Powerpoint, a partir } \\
\text { da observação do hipervídeo. O jogo deverá } \\
\text { envolver conhecimentos interdisciplinares } \\
\text { sobre o tema, bem como sobre o hipergênero, } \\
\text { e ressaltar aspectos intrassemióticos e } \\
\text { intersemióticos relativos aos textos. } \\
\text { - Interação entre os alunos, analisando a } \\
\text { temática, o hipergênero e as atividades } \\
\text { desenvolvidas, por meio de postagens na } \\
\text { rede social Facebook. O professor deverá } \\
\text { criar um grupo específico para a turma. }\end{array}$ \\
\hline & $\begin{array}{c}\text { Módulo 2: } \\
\text { CONCEITUALIZAÇÃO }\end{array}$ & Construindo ideias & $\begin{array}{l}\text { - Observação de tutorial para produção de } \\
\text { hipervídeos em programa de apresentação } \\
\text { eletrônica; } \\
\text { - Produção de cartaz com a apresentação de } \\
\text { dicas para a produção de hipervídeos. As } \\
\text { dicas englobarão critérios intersemióticos e } \\
\text { intrassemióticos relativos ao hipergênero. } \\
\text { Além disso, o professor deverá orientar o } \\
\text { aluno a produzir o cartaz utilizando diferentes } \\
\text { semioses e atentando-se para a necessidade } \\
\text { da utilização de diferentes fontes, cores, } \\
\text { formatos de papel, etc. Para a produção, os } \\
\text { alunos poderão usar um programa específico } \\
\text { para a criação de desenho ou produção de } \\
\text { cartazes. } \\
\text { - Postagens dos cartazes criados no grupo } \\
\text { criado na rede social e possível diálogo entre } \\
\text { os alunos acerca das produções. }\end{array}$ \\
\hline & $\begin{array}{l}\text { Módulo 3: } \\
\text { ANÁLISE }\end{array}$ & $\begin{array}{l}\text { Compartilhando o } \\
\text { conhecimento }\end{array}$ & $\begin{array}{l}\text { - Seleção de três diferentes vídeos/hipervídeos } \\
\text { para observação/ análise, dentre os vídeos } \\
\text { disponibilizados pelo professor em arquivo digital; } \\
\text { Comparação entre os diferentes } \\
\text { vídeos/hipervídeos e seleção daquele(s) } \\
\text { considerado(s) hipervídeo(s), conforme os os } \\
\text { propósitos do gênero textual e as dicas/conceitos } \\
\text { criados no módulo } 2 \text {. } \\
\text { - Diálogo entre os alunos sobre a seleção feita e } \\
\text { argumentação acerca das ideias, por meio de } \\
\text { postagens no grupo criado na rede social } \\
\text { Facebook. }\end{array}$ \\
\hline & $\begin{array}{l}\text { Módulo 4: } \\
\text { APLICAÇÂAO }\end{array}$ & $\begin{array}{l}\text { Produzindo } \\
\text { hipervídeos }\end{array}$ & $\begin{array}{l}\text { - Produção de hipervídeos sobre o uso das } \\
\text { tecnologias digitais e o cyberbullying; } \\
\text { - Escolha e audição de diferentes músicas; } \\
\text { - Seleção de diferentes gêneros de textos } \\
\text { verbais e não verbais para leitura e análise; } \\
\text { - Seleção de músicas e imagens para } \\
\text { inserção nos vídeos; } \\
\text { - Seleção e produção de diferentes gêneros } \\
\text { de textos para inserção nos vídeos; } \\
\text { - Revisão dos vídeos, observando os formatos } \\
\text { de letras, as cores e as imagens e músicas } \\
\text { inseridas na produção. } \\
\text { - Exibição dos hipervídeos produzidos em } \\
\text { projetor de multimídia; } \\
\text { - Observação e análise dos vídeos pelos } \\
\text { colegas; } \\
\text { - Para a avaliação das atividades realizadas } \\
\text { na proposta didática, os alunos poderão } \\
\text { postar mensagens diversas no grupo criado } \\
\text { na rede social Facebook. }\end{array}$ \\
\hline
\end{tabular}


Sem dúvida, a proposta elaborada pode contribuir para os multiletramentos de estudantes matriculados nos anos finais do ensino fundamental, já que a convivência com diversos gêneros de textos em ambientes digitais, bem como a aprendizagem de aspectos inter e intrassemióticos que envolvem a constituição dos textos, favorece o desenvolvimento das práticas de leitura e escrita, funcionando como uma importante estratégia de aprendizagem. Através da associação entre diferentes semioses, as interações desenvolvidas nos ambientes virtuais por meio da construção dos hipervídeos possibilitarão a compreensão dos diferentes modos de representação do significado. Além disso, a produção dos textos e dos hipervídeos em diferentes situações interacionais promove a criatividade e a autonomia dos sujeitos, ajudando-os a lidar com um mundo cada vez mais digital.

De modo geral, a proposta pedagógica foi elaborada no intuito de promover o uso social da leitura e escrita, fundamentando-se na Pedagogia dos Multiletramentos. Assim, as atividades foram segmentadas nas seguintes etapas: experimentação, conceitualização, análise e aplicação. No que concerne à etapa de experimentação, foi proposta com o objetivo de propiciar ao estudante a integração entre o conhecimento prévio e novos conhecimentos relacionados ao gênero vídeo, ao tema cyberbullying e aos aspectos inter e intrassemióticos presentes na constituição dos textos. Esses conhecimentos serão apreendidos pelos alunos, inicialmente, por meio da observação do hipervídeo e, posteriormente, através do jogo Quiz e das discussões promovidas na rede social.

Já o processo de conceitualização ocorrerá por meio da produção dos cartazes digitais, com base nas reflexões feitas no módulo de experimentação e nas instruções apresentadas no vídeo tutorial. Tratase, na verdade, de um processo geral e, ao mesmo tempo, individual, de construção de saberes em que o estudante conceitua, de modo prático, como diferentes textos se constituem e cria uma metalinguagem para ser utilizada nas práticas posteriores.
A análise, por sua vez, perpassa todas as atividades e módulos propostos. No entanto, desenvolve-se de modo mais específico no módulo 3 , no qual o aluno é instigado a testar os conceitos anteriormente construídos, por meio da seleção/comparação entre vídeos, e a argumentar acerca de suas ideias. Nesse caso, além da análise, ocorre à ampliação e/ou reconstrução de conhecimentos.

Por fim, na fase de aplicação dos conhecimentos, o aluno é estimulado a usar os conhecimentos apreendidos de diferentes modos: i) por meio da produção do hipervídeo; ii) através da análise das produções dos colegas; iii) a partir do diálogo com os demais participantes da atividade.

Portanto, é possível afirmar que o trabalho com hipergêneros multimodais em ambientes digitais pode trazer importantes contribuições para o desenvolvimento dos multiletramentos na escola, seja por propiciar a realização das atividades de leitura e escrita de maneira mais dinâmica e interativa, despertando a criatividade e autonomia dos alunos; seja por oportunizar o conhecimento acerca de diferentes gêneros/hipergêneros textuais; ou, ainda, por promover diferentes estratégias de representação do significado por meio dos aspectos inter e intrasemióticos de constituição dos textos. Tudo isso revela o quão importante são as estratégias de multiletramentos no processo de ensino e aprendizagem da língua portuguesa.

\section{Conclusão}

O presente trabalho objetivou demonstrar como o trabalho com gêneros/hipergêneros multimodais, por meio da utilização das interfaces digitais, pode colaborar para o desenvolvimento das práticas de letramentos nos anos finais do ensino fundamental. Compreendendo que a análise deveria conciliar a Teoria dos Multiletramentos com os pressupostos educacionais contemporâneos que valorizam a importância do uso das tecnologias digitais no processo de ensino e aprendizagem dos sujeitos, promoveram-se reflexões acerca dos 
mecanismos linguísticos e interacionais e diferentes modos (intersemióticos e intrasemióticos) de significação que emergiram a partir do uso da língua em contextos digitais. Em seguida, foi apresentada uma sequência didática para 0 trabalho com estudantes matriculados nos anos finais do ensino fundamental. De maneira geral, a proposta demonstrou como as diferentes etapas de multiletramentos podem contribuir para a construção/reconstrução de saberes e redesigning dos sujeitos, já que - à medida que reorganiza o conhecimento, o indivíduo também reconfigura seus olhares acerca do mundo no qual está inserido.

Certamente, as reflexões e as propostas apresentadas neste trabalho reiteram, no mínimo, três aspectos relevantes em relação à aprendizagem da língua portuguesa em contextos digitais: i) na contemporaneidade, as práticas de letramentos devem contemplar atividades diversificadas e multimodais (que envolvam, inclusive, a compreensão dos aspectos intersemióticos e intrassemióticos presentes nos textos); ii) é necessário que as práticas de letramento sejam sempre atuais e atualizadas, sendo crucial - portanto - a utilização das tecnologias digitais, de modo interativo e dinâmico; iii) as diferentes etapas dos multiletramentos (experimentação, conceitualização, análise e aplicação) são fundamentais para que os sujeitos construam/reconstruam saberes, à medida que constituem a si próprios.

Portanto, esperamos que este trabalho possa auxiliar pesquisadores e professores que atuam na educação básica, com discussões sobre novas possibilidades de letramento, contribuindo para a ampliação e valorização do uso das tecnologias digitais no processo de ensino e aprendizagem da leitura e da escrita no contexto escolar.

\section{Referências}

ALVES, L. R. G. Novas Tecnologias: instrumento, ferramenta ou elementos estruturantes de um novo pensar? Revista da FAEEBA. Salvador: p.141-152, 1998.

COPE, B.; KALANTZIS, M. 'Multiliteracies: New Literacies, New Learning'. Pedagogies: An International Journal, vol.4, 2009, p.164-195.

KRESS, G. Multimodality. In: COPE, B.; KALANTZIS, M. (Ed.). Multiliteracies: literacy learning and the design of social futures. London: Routledge, 2000. p.182-202.

VAN LEEUWEN, T. Reading images: The grammar of visual design. London; New York: Routledge, 2006 [1996].

MARQUES, C. P. C. et al. Computador e ensino: uma aplicação à língua portuguesa. São Paulo: Ática, 1986.

NIC.br - Núcleo de Informação e coordenação do Ponto BR. Educação e tecnologias no Brasil [livro eletrônico]: um estudo de caso longitudinal sobre o uso das tecnologias de informação e comunicação em 12 escolas públicas. 1. ed. São Paulo: Comitê Gestor da Internet no Brasil, 2016. Disponível em: $<$

http://cetic.br/media/docs/publicacoes/7/EstudoSet orialNICbrTICEducacao.pdf>. Acesso em: 02 jul. 2017.

THE NEW LONDON GROUP. A pedagogy of multiliteracies: Designing social futures. Harvard Educational Review, 66(1), 60-92, 1996.

\section{COMO CITAR ESSE ARTIGO}

SANTOS, Fernanda Maria Almeida dos. Multiletramentos e ensino de língua portuguesa na educação básica: uma proposta didática para o trabalho com (hiper)gêneros multimodais. Signo, Santa Cruz do Sul, v. 43, n. 76, mar. 2018. ISSN 1982-2014. Disponível em: <https://online.unisc.br/seer/index.php/signo/article/view/10671>. Acesso em: doi: http://dx.doi.org/10.17058/signo.v43i76.10671. 